\title{
Research on Risk Management of Emergencies in Supply Chain
}

\author{
Chunqiu $\mathrm{Xu}$, Changyu Hu* Lipeng Wang \\ School of Management Engineering,Zhengzhou University,Zhengzhou 450001,china \\ * Corresponding author 2281778952@qq.com
}

Keywords: supply chain risk, disruption management, emergency, influencing factors, prevention strategies

\begin{abstract}
In this paper, first of all, from the perspective of supply chain, the related theory of supply chain risk management and emergency is analysed and discussed in detail. Based on the supply chain of emergencies emergency management, the paper puts forward the coping strategies of supply chain risk. And the establishment of the model and example analysis proves that the supply chain related to the use of emergency supply chain strategy will reduce the loss of the supply chain, greatly improving the effectiveness of the supply chain as a whole.
\end{abstract}

\section{INTRODUTION}

With the rapid development of economy, modern enterprises facing the market competition are no longer the traditional enterprises and the competition between the enterprises, but turned to the competition between supply chain and supply chain, supply chain risk management problem has aroused the concern from all walks of life. however, lead to changes in the size of the market, will be on the normal operation of the supply chain of the whole system have a significant impact, many of the normal operation of supply chain enterprise to a halt, or even bankruptcy. Therefore, establishing respond to emergencies emergency management of supply chain system has very important theory value and practical significance.

\section{LITERATURE REVIEW}

Emergency management for supply chain emergencies can be said to be a new field of research in supply chain risk management. Many scholars have analyzed the risk management of supply chain in different ways. Reference [2] study the optimal strategy of reorganization based on quantitative discount contract when the emergent events make the market demand disturbance. In reference [3] the optimal production plan, the optimal wholesale price and the optimal retail price of the supply chain have certain robustness, and the relevant conclusions are verified by numerical simulation. Based on the influence of emergencies, the topological structure of the supply chain and the type of contract, the research results of the supply chain contract coordination and coordination are summarized and summarized in reference [4]. Reference [5] analyzed emergencies through the technology, the environment and the supply chain structure and other factors impacting the supply chain.

In this paper, the risk of supply chain according to its occurrence probability and the impact of the ex post weight is divided into the following two categories: one is the probability of occurrence of small, which is difficult to control the risk of emergencies after the impact of large; the secondly the daily operational risks which is the probability of occurrence and less risky is easy to control.

\section{SUPPLY CHAIN EMERGENCY SYSTEM STRATEGY OF MATHEMATICAL MODEL}

\subsection{Model description and assumptions}

The symbols are as follows:

A: Indicates a specific supply chain emergency strategy

$\mathrm{t}_{1}$ : Indicates the daily operational risk associated with its supply chain; $\mathrm{T} 1$ indicates its set.

$\mathrm{t}_{2}$ : Indicates Supply chain contingency risk; T2indicates its set.

In order to quantify the impact of those risks on the supply chain, two basic measures are introduced, both of which are related to the input costs of A. (1) the probability that the supply chain is affected by the risk; (2) the loss suffered by the supply chain under the influence of the risk.

$\mathrm{C}$ : indicates the cost in $\mathrm{A}(\mathrm{C}=0$, indicates that $\mathrm{A}$ is not used).

$P_{1}(C)$ : That A's input cost is $\mathrm{C}$, the supply chain is affected $T_{1}$ by the probability.

$H_{1}(C)$ : Indicates the supply chain average loss suffered by $T_{1}$ when the input cost of A is C.

$H_{1}(0)$ : That does not use $\mathrm{A}$, the supply chain average lossunder the influence of $T_{2}$

$P_{2}(C)$ : Indicates the probability that the supply chain is affected by $T_{2}$ when the input cost of A is C.

$\mathrm{H}_{2}(\mathrm{C})$ : Indicates the average loss suffered by $T_{2}$ the supply chain when A's input cost is $C$. 


\subsection{The establishment of and solution to the model}

The first case: the assumption that $T_{2}$ did not occur, a response to the effectiveness of $T_{1}$

Assumption $\mathrm{S}$ is the supply chain average profit that is neither affected by $T_{1}$ nor affected by $T_{2}$. From the above analysis, in the absence of $T_{2}$, the input cost of $\mathrm{C}$ is to maximize the expected profit of the supply chain, which is $F\left(P_{1}(C), C\right)$

$$
\operatorname{Max} F\left(P_{1}(C), C\right)=S-P_{1}(C) H_{1}(C)-C
$$

There are some circumstances for formula (1), when the relationship is specifically analyzed:

(1) In the absence of $A$, which means that $C=0$

Assuming that the supply chain is not affected by $T_{1}$, its supply chain profit is as follow:

$$
F\left(P_{1}(C), C\right)_{11}=S
$$

Assuming that the supply chain that is affected by $T_{1}$ suffered a loss, its supply chain profit is as follow:

$$
F\left(P_{1}(C), C\right)_{11}=S-H_{1}(0)
$$

(2) In the adoption of $A$, which means that $C \neq 0$

Assuming that the supply chain is not affected by $T_{1}$, its supply chain profit is as follow:

$$
F\left(P_{1}(C), C\right)_{11}=S-C
$$

Assuming that the supply chain that is affected by $T_{1}$ suffered a loss, its supply chain profit is as follow:

$$
F\left(P_{1}(C), C\right)_{22}=S-H_{1}(C)-C
$$

According to formula (2) and formula (4), when the supply chain has not been affected by the influence of $T_{1}$, the reduction of the supply chain profit $\Delta F\left(P_{1}(C), C\right)_{1}$ is as follow :

$$
\begin{aligned}
& \Delta F\left(P_{1}(C), C\right)_{22} \\
& =F\left(P_{1}(C), C\right)_{11}-F\left(P_{1}(C), C\right)_{21} \\
& =S-S+C \\
& =C
\end{aligned}
$$

According to formula (3) and formula (5), when the supply chain has not been affected by the influence of $T_{1}$, the supply chain profit $\Delta F\left(P_{1}(C), C\right)_{1}$ which business decision-makers save the loss saved by the adoption of $\mathrm{A}$ is as follow :

$$
\begin{aligned}
& \Delta F\left(P_{1}(C), C\right)_{2} \\
& =F\left(P_{1}(C), C\right)_{22}-F\left(P_{1}(C), C\right)_{12} \\
& =S-H 1(C)-C-S+H_{1}(0) \\
& =H_{1}(0)-H_{1}(C)-C
\end{aligned}
$$

To enable $A$ reflecting the validity of $T_{1}$, the following inequality must be satisfied:

$$
P_{1}(C) \Delta F\left(P_{1}(C), C\right)_{2} \geq\left(1-P_{1}(C) \Delta F\left(P_{1}(C), C\right)_{1}\right.
$$

That is

$$
C \leq P_{1}(C)\left(H_{1}(0)-H_{1}(C)\right)
$$

The second case: when an incident $T_{2}$ occurs, A exists on the effectiveness of the incident of $T_{2}$. For this type of supply chain risk, it is supposed to minimize the expected loss of $\mathrm{Q}\left(P_{2}(C), C\right)$ by defining the input cost C,

$$
\operatorname{Min}\left(P_{2}(C), C\right)=P_{2}(C) H_{2}(C)
$$

That is equivalent to formula (10)

$$
\operatorname{Max}-\mathrm{Q}\left(P_{2}(C), C\right)=-P_{2}(C) H_{2}(C)
$$

Because the degree of importance of the decision makers is different, the objective function formula (1) and formula (10) are weighted and merged by introducing two weight coefficients which is $\theta_{1}$ and $\theta_{2}, \theta_{1}$ and $\theta_{2}$ is respectively representative to the decision-makers on the degree of attention, $\theta_{1}, \theta_{2} \in[0,1], \theta_{1}+\theta_{2}=1$. The greater the value $\theta_{1}$, the greater the importance of A to $T_{1}$. On the other hand the greater the value of $\theta_{2}$ the greater the importance of A to $T_{2}$, the greater the degree of effectiveness of the decision maker's response to A.It meas that the loss of the supply chain is as small as possible

In summary, the optimization model for establishing A is as follows:

$$
\begin{array}{r}
\operatorname{Max} \theta_{1}\left(S-P_{1}(C) H_{1}(C)-C\right)+\theta_{2}\left(-P_{2}(C) H_{2}(C)\right) \\
\text { s.t. }\left\{\begin{array}{l}
C \leq P_{1}(C)\left(H_{1}(0)-H_{1}(C)\right) \\
\theta 1+\theta 2=1 \\
C \geq 0 \\
\theta_{1} \geq 0, \quad \theta_{2} \geq 0
\end{array}\right.
\end{array}
$$

For the above-mentioned supply chain emergency strategy model, it is a single objective optimization model. On the basis of given sample data and weight coefficient of $\theta_{1}$ and $\theta_{2}$, it can be solved directly, and the optimal solution is defined as $C^{*}$. If $C^{*}=0$, the decision makers does not use the supply chain contingency strategy $\mathrm{A}$. If $C^{*} \neq 0$, it means that the decision maker needs to put in the cost of $C^{*}$ to implement strategy A.

\section{CASE STUDY}

In order to have a clearer understanding of the model and related issues, the following for the emergency inventory strategy gives a specific case study. The following is a mobile phone manufacturer (W) as a core business supply chain as an example to analyze.

The manufacturer's consideration of the use of A for a key component is intended to effectively cope with the shortage of parts caused by interference with the risk, and to reduce the interruption of the supply process huge 
loss by the impact of $T_{2}$.

It assume that the probability of supply chain being affected is $50 \%$ and $8 \%$, respectively. In the supply chain in the case of $T_{1}$ occurring, in the case of the shortage of the parts of the probability is $50 \%$; supply chain interference caused by $T_{2}$, the procurement of parts of the probability of interruption is $8 \%$. In the case of suffering $T_{1}$ and $T_{2}$, the average monthly loss of 200,000 RMB and 10 million RMB. Supply chain in the case without any risk of the case, the average monthly profit is up to 20 million. The cost of the supply chain and the impact will be reduced by $2 \%$ and $1.5 \%$ for each additional cost of $\$ 0.1$ million. Under the influenced by $T_{1}$ and $T_{2}$, the average loss per month is reduced by $4 \%$ and $3 \%$ respectively. The results are as follows:

$$
\begin{aligned}
& P_{1}(C)=2000 \\
= & \max \left\{50 \%\left(1-\frac{\mathrm{c}}{0,1} \times 2 \%\right), 0\right\} \\
= & \max \{0.5-0.1 C, 0\} \\
& H_{1}(C) \\
= & \max \left\{20\left(1-\frac{\mathrm{c}}{0.1} \times 4 \%\right), 0\right\} \\
= & \max \{20-80 C, 0\} \\
P_{2}(C) & \max \left\{80 \%\left(1-\frac{\mathrm{c}}{0.1} \times 1.5 \%\right), 0\right\} \\
= & \max \{0.08-0.012 C, 0\} \\
H_{2}(C) & \max \left\{1000\left(1-\frac{\mathrm{c}}{0.1} \times 3 \%\right), 0\right\} \\
= & \max \{1000-300 C, 0\}
\end{aligned}
$$

Substituting the known condition into the above model, the optimal solution and its target value $\mathrm{E}$ can be obtained according to the different combinations of weight coefficients. As the $\theta_{1}$ and $\theta_{2}$ Satisfy the relationship of $\theta_{1}+\theta_{2}=1$, this paper only discuss the corresponding optimal solution of $C^{*}$ and the effect on the target value of $\mathrm{E}$ when the weight coefficient of $\theta_{1}$ changes.The results are as follows:

Table 1 The optimal solution $C^{*}$ and the target value $\mathrm{E}$ when the weight coefficient $\theta_{1}$ changes

\begin{tabular}{c|c|c|c}
\hline$\theta_{1}$ & {$\left[0, \frac{12}{13}\right]$} & $\left(\frac{12}{13}, \frac{18}{19}\right)$ & {$\left[\frac{18}{19}, 1\right]$} \\
\hline$C^{*}$ & $\frac{10}{3}$ & $\frac{36-37 \theta_{1}}{7.2-7.2 \theta_{2}}$ & $\frac{10}{4}$ \\
\hline
\end{tabular}

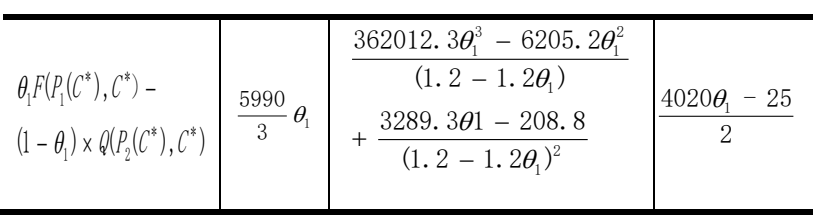

It is obtained from Table 1 above that $\forall \theta_{1} \in[0,1], \quad C^{*}=0$. That is the optimal decision is to use A with any value of $\theta_{1}$. The firstly For $\theta 1 \in\left[0, \frac{12}{13}\right]$, $C^{*}$ is a definite constant with $C^{*}=\frac{10}{3}$, and $\mathrm{E}$ is equal to $\frac{5990}{3} \theta_{1}$. The secondly if $\theta_{1}$ is belong to $\left[\frac{12}{13}, \frac{18}{19}\right], C^{*}$ and $\mathrm{E}$ is a function of $\mathrm{x}$. The lastly if $\theta_{1}$ is belong to $\left[\frac{18}{19}, 1\right]$ and $C^{*}$ is a definite constant with $C^{*}=\frac{10}{4}, \mathrm{E}$ is equal to $\frac{4020 \theta_{1}-25}{2}$.

\section{CONCLUSIONS}

This paper firstly analyzes the risk from the perspective of the supply chain, puts forward the factors that affect the emergency management of the supply chain under the emergencies, and establishes the corresponding emergency system. The establishment of enterprise supply chain need a certain cost. Considering the supply chain enterprises to consider whether to choose the emergency strategy, a supply chain emergency strategy model which is an optimized mathematical model is established, and empirical analysis for emergency inventory strategy is built to test and verify it. The final results: supply chain enterprises to use the relevant emergency inventory strategy can effectively Deal with emergencies.

The shortcomings of this paper: the source of supply chain risk, the degree of impact vary and the use of emergency strategies are not the same, this paper only put forward two simple emergency strategy, and did not take into account all the circumstances. After empirical analysis, no specific quantitative validation was performed.

\section{ACKNOWLEDGEMENTS}

This research is supported by National Natural Science Foundation of China (Grant No. 71702172), Humanities \& Social Sciences Research Foundation of Ministry of Education of China (Grant No. 15YJC630148), Distinguished Young Teacher Development Foundation of Zhengzhou University (1421326092), and Key Research Foundation of University Education in Henan province (17A520058). The authors would like to thank the editors and anonymous referees for their careful and fruitful comments to improve the quality of this paper. 


\section{REFERENCES}

[1] CHENG S, LU H, Coordination of Supply Chain under Disruptions with Quantity Discount Contract, Journal of Logistics Engineering and Management, no 7. pp. 119-121, (2015).

[2] WU Z.H,CHEN H, ZHAO Q.Supply Chain Coordination Model under Asymmetric information and Disruptions,Journal of Systems \& Management, no.24(1),pp.91-97,( 2015).

[3] WU X.H, YAO X, YIN X.J,Research Review of Supply Chain Coordination by Contract under Emergency, Journal of Science and Technology Management Research, Vol.35; No.334(12), pp.188-193,(2015)

[4] ZHU X.Q,Impact of Emergencies on Supply Chains, Logistics Engineering and Management, no.36(4), pp. 61-64, (2014)

[5] Zhang J.Y,Research on Prevention Strategies of Supply Chain Risk Basedon the Emergency Events.Beijing Jiaotong University of master's degree thesis printed wersion,(2013).

[6] Wu W. The Effect of Emergencies-based Supply Chain Risk on Firm Performance, Beijing Jiaotong University of master's degree thesis printed wersion,(2014)

[7] Guo L,Zhou R.H,Study on Risk Analysis and Emergency Strategy of Outbreaking Events in Tourist Product Supply Chain,Journal of Logistics Technology, no.32(7),pp. 211-213, (2013).

[8] Qiao F,An Analysis of Risk Management in Retail Supply Chain - A Case Study of Mei Te Hao,China Economist,no. 4,pp.52-53,(2014).

[9] Li X.M ,Study on Coordination of Multiple Retailers in Responding to Supply Chain Outbreak Incidents,Journal of Logistics Technology,no.11,pp.276-278,(2014).

[10] Li M, Hu H, Analysis and Emergency Countermeasures of Outbreak Events in Tourism Product Supply Chains,ournal of Logistics Technology,no.23,pp.385-386,(2014). 